\title{
Recurrence of Pulmonary Embolism in Young Man With Retroperitoneal Tumor Despite Insertion of Temporary IVC Filter
}

\author{
Masahiro Natsuaki, MD; Kotaro Numaguchi, MD; Hideo Tada, MD*; \\ Yuichiro Nakashima, MD**; Masanori Okabe, MD; Yusuke Yamamoto, MD
}

\begin{abstract}
Pulmonary embolism (PE) is a fatal disease that is very rare in young people. A 21-year-old man developed PE because of a retroperitoneal tumor. The inferior vena cava (IVC) was obstructed by the tumor, and thrombus existed in the right common iliac vein. Thrombolysis and heparinization improved his symptoms prior to urgent tumor resection. A temporary IVC filter was inserted the day before the operation, but $8 \mathrm{~h}$ later fatal massive PE occurred. At autopsy, the retroperitoneal tumor was revealed as a metastatic choriocarcinoma. Prophylactic use of a temporary IVC filter might have paradoxically induced recurrence of massive PE in this case. (Circ J 2009; 73: $1756-1758$ )
\end{abstract}

Key Words: IVC filter; Pulmonary embolism; Retroperitoneal tumor

\section{Case Report}

A 21-year-old man was admitted to our hospital for acute chest pain and dyspnea. On arrival, his blood pressure was $110 / 40 \mathrm{mmHg}$ and heart rate was 112 beats $/ \mathrm{min}$. In the arterial blood gas analysis, $\mathrm{pH}$ was $7.43, \mathrm{PaCO}_{2}$ was $31 \mathrm{mmHg}$, and $\mathrm{PaO}_{2}$ was $92 \mathrm{mmHg}$ under $10 \mathrm{~L} / \mathrm{min}$ oxygen inhalation. In the blood tests, blood cell count and renal functions were normal, but lactate dehydrogenase and C-reactive protein levels were high at $590 \mathrm{IU} / \mathrm{L}$ and $3.7 \mathrm{mg} / \mathrm{dl}$, respectively. Of the coagulation values, the d-dimer level was high $(13.7 \mu \mathrm{g} / \mathrm{ml})$, and ATIII activity was slightly low $(60 \%)$, but the activities of protein $\mathrm{C}$ and protein $\mathrm{S}$ were normal. Plain chest X-ray showed mild pulmonary artery dilatation. Ultrasonic cardiogram (UCG) showed right ventricle overload and pulmonary hypertension (estimated systolic pulmonary artery pressure $60 \mathrm{mmHg}$ ). We suspected pulmonary embolism (PE), and performed contrast computed tomography $(\mathrm{CT})$, which revealed massive thrombi in both pulmonary arteries (Figure 1A). Bilateral perfusion defects were found on perfusion scintigraphy of the lung (Figure 1B), and we diagnosed PE. In addition, abdominal CT showed a retroperitoneal tumor approximately $10 \times 5 \mathrm{~cm}$ (Figure 2A). The inferior vena cava (IVC) was obstructed by the tumor and thrombus existed in the right common iliac vein. We started thrombolysis (urokinase 240,000 U/day for 5 days) followed by heparinization (48,000 U/day). We controlled the APTT at 60-80s. Under this therapy, his oxygen saturation and symptoms improved each day and on the $3^{\text {rd }}$ day, arterial blood gas analysis showed that $\mathrm{pH}$ was $7.43, \mathrm{PaCO}_{2}$ was $40 \mathrm{mmHg}$, and $\mathrm{PaO}_{2}$ was $88 \mathrm{mmHg}$ under room air. The pulmonary artery pressure had also decreased on UCG (estimated systolic pulmonary artery
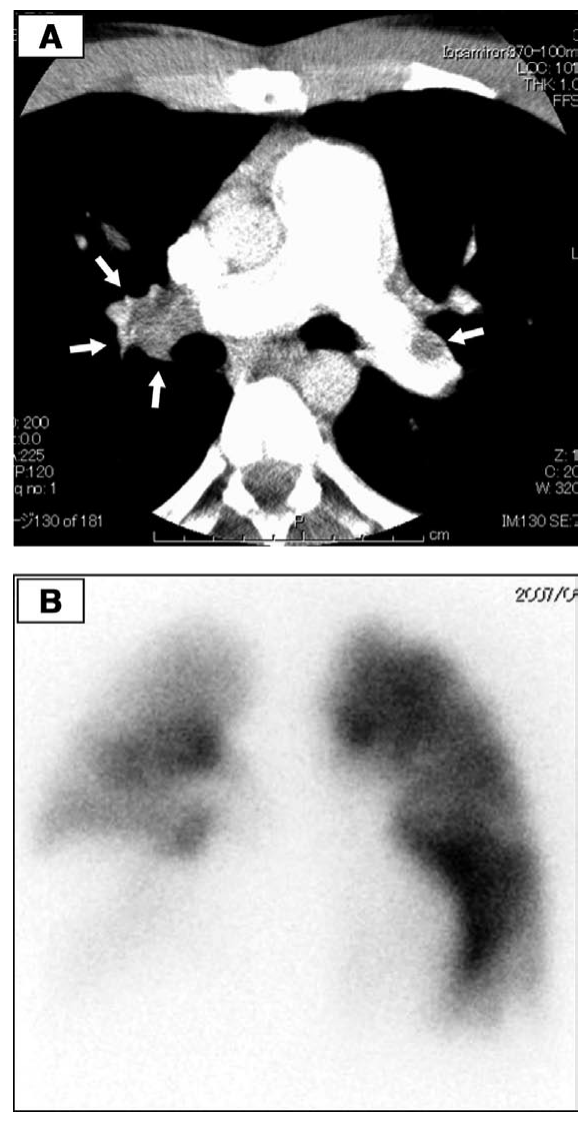

Figure 1. Contrast-medium enhanced computed tomography of the chest (A) shows thrombi (arrows) in both pulmonary arteries. Bilateral perfusion defects are seen on perfusion scintigraphy of the lung $(\mathbf{B})$.

(Received May 8, 2008; revised manuscript received August 16, 2008; accepted September 4, 2008; released online January 14, 2009)

Department of Cardiology, Saiseikai Fukuoka Hospital, *Department of Cardiology and **Department of Anatomical Pathology, Kyushu University, Fukuoka, Japan

Mailing address: Masahiro Natsuaki, MD, Department of Cardiology, Saiseikai Fukuoka Hospital, 1-3-46 Tenjin, Chuo-ku, Fukuoka 810-0001, Japan. E-mail: natsuaki@ saiseikai-hp.chuo.fukuoka.jp

All rights are reserved to the Japanese Circulation Society. For permissions, please e-mail: cj@j-circ.or.jp 

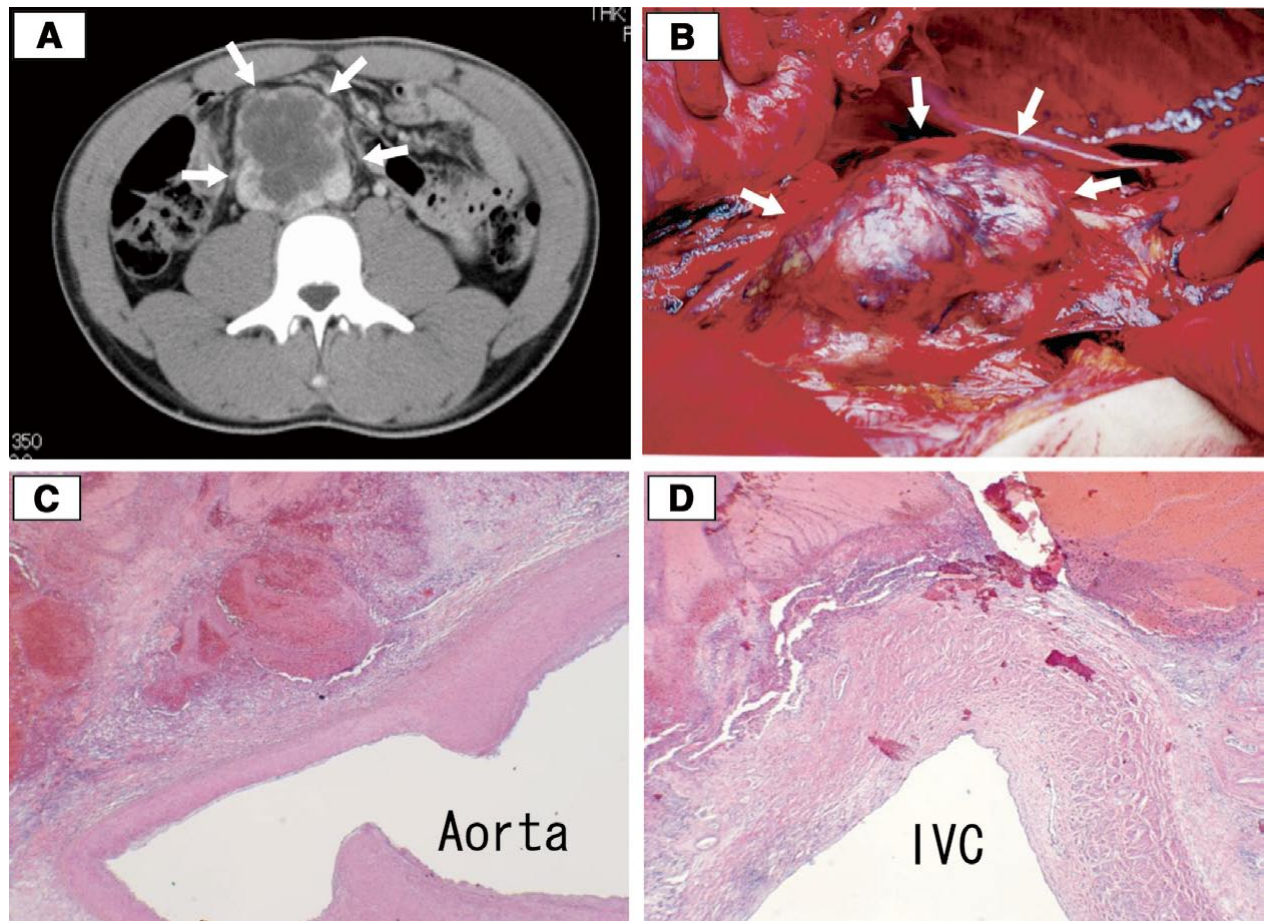

Figure 2. Contrast-medium enhanced computed tomography of the abdomen (A) shows the retroperitoneal tumor (arrows). (B) Macroscopic appearance of the tumor. Microscopic findings show tumor invasion to the external surface of the abdominal aorta (C) and inferior vena cava (IVC) (D). There is no evidence of invasion of the internal surfaces.

pressure $20 \mathrm{mmHg}$ on the $6^{\text {th }}$ day). Because it was suspected that the tumor had invaded the abdominal aorta and IVC, tumor resection was urgent and he was transferred to the university hospital on the $6^{\text {th }}$ day.

Heparinization was continued and the d-dimer level decreased daily $\left(5.2 \mu \mathrm{g} / \mathrm{ml}\right.$ on the $7^{\text {th }}$ day). The operation was planned for the $8^{\text {th }}$ day, and the surgeon requested a temporary IVC filter to avoid perioperative PE. The day before surgery, a filter (Neuhaus Protect ${ }^{\mathrm{TM}}$, Toray Industries Inc, Tokyo, Japan) was inserted from the jugular vein and put it in the proximal IVC near the right atrium (Figure 3) instead of below the renal vein as is usual, because of the retroperitoneal tumor. The $8 \mathrm{~h}$ later, the patient's blood pressure suddenly dropped, and he fell into shock. Emergency UCG showed a huge thrombus in the right atrium and collapse of the left ventricle (Figure 4). Although heparinization had continued after the IVC filter insertion (APTT $82.9 \mathrm{~s}$, platelet count $188,000 / \mu \mathrm{l}$ at the time of developing shock), it appeared that a new thrombus had been produced on the filter itself. He died shortly after, despite attempts at resuscitation.

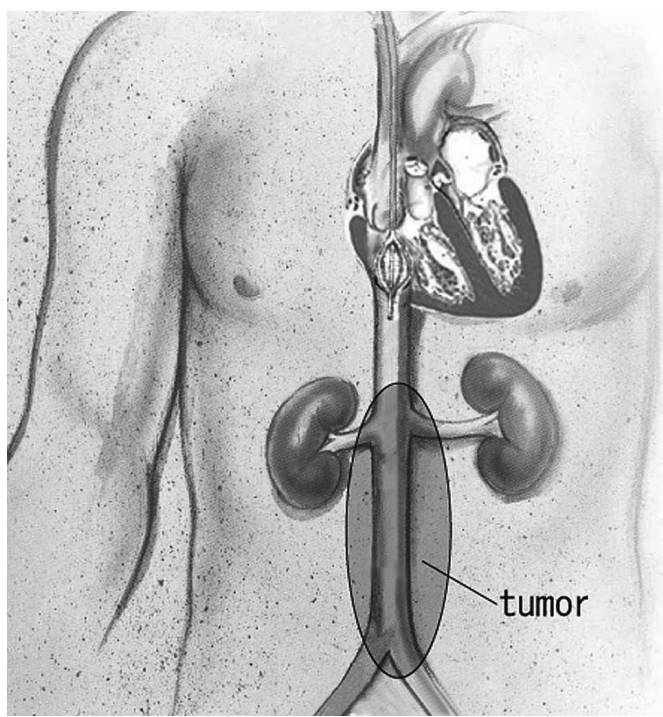

Figure 3. Position of inserted inferior vena cava filter.
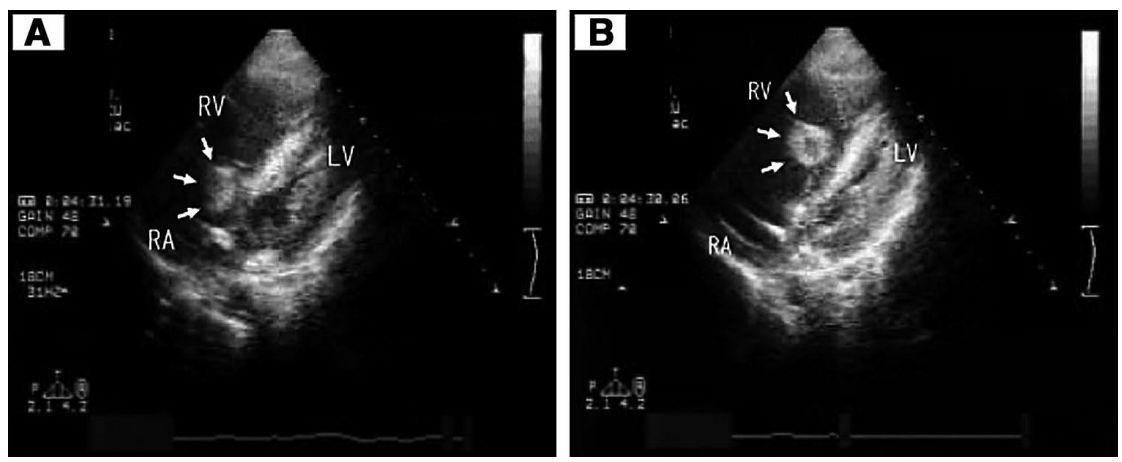

Figure 4. Ultrasonic cardiogram taken at the time of developing shock shows a huge thrombus (arrows) in the right atrium (RA) (A), which moves into the right ventricle (RV) (B). LV, left ventricle. 
Significant thrombus on the filter was not found at the time of autopsy. Multiple organized and fresh thrombi were detected within the proximal and distal sections of both pulmonary arteries. Organized thrombi were also found in the right iliac vein. Venous thrombus in the proximal IVC was not located, nor was there thrombus in the jugular vein at the site of insertion of the IVC filter. There was a serous pericardial effusion $(45 \mathrm{ml})$. Histological findings showed that the retroperitoneal tumor was a choriocarcinoma. There was evidence of invasion of the external surfaces of the abdominal aorta (Figure 2C) and IVC (Figure 2D), but none of invasion of the internal surfaces. We found intratubular malignant germ cells in the right testis, which is the so-called "burn out" tumor. From these findings, we diagnosed the retroperitoneal tumor as a metastatic choriocarcinoma from the right testis to the retroperitoneal lymph node. The retroperitoneal tumor had oppressed the IVC, resulting in PE, and furthermore, it was considered that the temporary IVC filter might have paradoxically caused recurrence of massive PE in this case.

\section{Discussion}

An IVC thrombus is generally produced by external compression, by a tumor or hematoma, a dysfunctional coagulation system, iatrogenic causes and so on. Renal cell carcinoma is the most common cause, ${ }^{1}$ but germ cell tumor, retroperitoneal leiomyosarcoma, adrenal cortical carcinoma, renal angiomyolipoma, and hepatic hemangioma have been reported as other causes. ${ }^{2-7}$

In this case, a germ cell tumor was associated with IVC thrombosis. Germ cell tumor is the most frequent malignancy in men aged 18-35 years. The majority of germ cell tumors present with only a testicular abnormality (approximately $50-70 \%$ ), 20-30\% present with metastatic disease and $2-5 \%$ with an extragonadal primary tumor. The most common sites of metastasis of a testicular germ cell tumor are the retroperitoneal lymph nodes, and IVC obstruction has been reported as a complication of metastatic testicular or primary retroperitoneal germ cell tumor. ${ }^{8-11}$ Bass et al reported that approximately $10 \%$ of patients with metastatic germ cell tumors had IVC obstruction, and right-side testicular primary tumors and abdominal masses measuring $>5 \mathrm{~cm}$ in maximum transverse dimension have the greatest risk of IVC obstruction. ${ }^{12}$ Therefore, the present patient had a high risk of IVC obstruction.

A temporary IVC filter is often used to avoid perioperative recurrence of $\mathrm{PE},{ }^{13}$ but filter-related complications sometimes occur ${ }^{14}$ and PE is an important one..$^{15}$ Thrombosis may occur at the insertion site or the site of the filter itself. Lorch et al reported a recurrence rate of PE after insertion of temporary IVC filter as $2.1 \% .{ }^{16}$ In this case, the patient had a recurrence of massive PE $8 \mathrm{~h}$ after insertion of a temporary IVC filter and suddenly died.

When we consider the cause of the recurrent PE in this case, the site of insertion of the IVC filter could be 1 reason for it. Because the tumor existed at the level of the renal vein, the site of the filter was relatively high (near the right atrium) and IVC flow might have been reduced by the tumor. These 2 factors might have influenced the formation of a thrombus on the filter itself and because the filter was located near the right atrium, the thrombus would tend to protrude into the cavity and become huge, resulting in fatal PE.

The timing of the operation may have been another cause of the recurrent PE. In the acute phase of PE, the blood coagulation system is often unstable and some tissue factors from the tumor can also induce hypercoagulation. We required a large amount of heparin to prolong the APTT $(48,000 \mathrm{U} / \mathrm{day})$, which may indicate a hypercoagulative state induced by tumor-related tissue factors and which could have influenced the formation of a thrombus on the filter. Because tumor invasion was suspected, surgery was considered to be urgent and if we could have delayed it, recurrence of PE might have been avoided.

The IVC filter is usually placed below the renal vein. If this cannot be achieved, the possibility of iatrogenic PE must be considered. Also, operation in the acute phase of PE should be avoided if at all possible.

\section{References}

1. Nesbitt JC, Soltero ER, Dinney CP, Walsh GL, Schrump DS, Swanson DA, et al. Surgical management of renal cell carcinoma with inferior vena cava tumor thrombosis. Ann Thorac Surg 1997; 63: 1592-1600.

2. O'Brien WM, Lynch JH. Thrombosis of the inferior vena cava by seminoma. J Urol 1987; 137: 303-305.

3. Kwok CK, Horowitz MD, Livingstone AS, Block NL. Mature testicular teratoma with vena cava invasion presenting as pulmonary embolism. J Urol 1993; 149: 129-131.

4. Hartman DS, Hayes WS, Choyke PL, Tibbetts GP. From the archives of the AFIP: Leiomyosarcoma of the retroperitoneum and inferior vena cava. Radiographics 1992; 12: 1203-1220.

5. Figueroa AJ, Stein JP, Lieskovsky G, Skinner DG. Adrenal cortical carcinoma associated with venous tumor thrombus extension. $\mathrm{Br} \mathrm{J}$ Urol 1997; 80: 397-400.

6. Gotoh A, Gohji K, Fujisawa M, Okada H, Arakawa S, Hanioka K, et al. Renal angiomyolipoma associated with inferior vena caval tumor thrombus. Br J Urol 1998; 81: 773-774.

7. Paolillo V, Sicuro M, Nejrotti A, Rizzetto M, Casaccia M. Pulmonary embolism due to compression of the inferior vena cava by a hepatic hemangioma. Tex Heart Inst J 1993; 20: 66-68.

8. Stockler M, Raghavan D. Neoplastic venous involvement and pulmonary embolism in patients with germ cell tumors. Cancer 1991; 68: $2633-2636$.

9. Fidias P, Fan CM, McGovern FJ, Wright CD, Kaufmann J, Grossbad ML. Intracaval extension of germ cell carcinoma: Diagnosis via endovascular biopsy and a review of the literature. Eur Urol 1997; 31: 376-379.

10. Sharifi R, Ray P, Schade SG, Lee M. Inferior vena cava thrombosis: Unusual presentation of a testicular tumor. Urology 1988; 32: 146150.

11. Spitz A, Wilson TG, Kawauchi MH, Ahlering TE, Skinner DG. Vena caval resection for bulky metastatic retroperitoneal metastatic germ cell tumors: An 18 year experience. J Urol 1997; 158: 1813-1818.

12. Bass H, Ken T, Richard W, Graham M. The management of inferior vena cava obstruction complicating metastatic germ cell tumors. Cancer 1999; 85: 912-918.

13. Wellons E, Rosenthal D, Schoborg T, Shuler F, Levitt A. Renal cell carcinoma invading vena cava: Use of a "temporary" vena cava filter to prevent tumor emboli during nephrectomy. Urology 2004; 63: 380-382.

14. Miyahara T, Miyata T, Shigematsu K, Deguchi J, Kimura H, Ishii S, et al. Clinical outcome and complications of temporary inferior vena cava filter placement. J Vasc Surg 2006; 44: 620-624.

15. Takahashi T, Fukuda I, Uchihashi Y, Satoh T. A patient with pulmonary thromboembolism after cesarean section, in spite of having a temporary IVC filter inserted. Masui 2004; 53: 280-283.

16. Lorch H, Welger D, Wagner V, Hillner B, Strecker EP, Herrmann H, et al. Current practice of temporary vena cava filter insertion: A multicenter registry. J Vasc Interv Radiol 2000; 11: 83-88. 